\title{
Experiment On Fluid Regime Under Different Rotate Velocity In Physical Simulation of Titanium Vertical Centrifugal Casting
}

\section{Yajun Yin}

Huazhong University of Science \& Technology

\section{Xin Peng}

Huazhong University of Science \& Technology

\section{Gen Xiao}

Huazhong University of Science \& Technology

\section{Xiwang Qie}

Huazhong University of Science \& Technology

\section{Xu Shen ( $\nabla$ shenxu@hust.edu.cn )}

Huazhong University of Science and Technology https://orcid.org/0000-0002-0268-507X

\section{Peng Wan}

Huazhong University of Science \& Technology

\section{Xiaoyuan Ji}

Huazhong University of Science \& Technology

Jianxin Zhou

Huazhong University of Science \& Technology

\section{Research Article}

Keywords: centrifugal casting of titanium alloy, physical simulation experiment, particle tracer technology, filling velocity, morphology

Posted Date: August 24th, 2021

DOl: https://doi.org/10.21203/rs.3.rs-739544/v1

License: (c) (1) This work is licensed under a Creative Commons Attribution 4.0 International License. Read Full License

Version of Record: A version of this preprint was published at The International Journal of Advanced Manufacturing Technology on February 2nd, 2022. See the published version at https://doi.org/10.1007/s00170-021-08516-y. 



\section{Experiment on fluid regime under different rotate velocity in}

\section{physical simulation of Titanium vertical centrifugal casting}

Yajun Yin, Xin Peng, Gen Xiao, Xiwang Qie, Xu Shen*, Peng Wan, Xiaoyuan Ji, Jianxin Zhou

(State Key Laboratory of Materials Processing and Die \& Mould Technology, Huazhong

University of Science \& Technology, Wuhan, Hubei, 430074, People's Republic of China)

Abstract: In this paper, the physical simulation of filling process of vertical centrifugal casting (VCC) of complex titanium alloy casting was studied. Combined with the mature PTV particle tracking technology, the high-speed photography pictures of the filling process of VCC at different rotational speeds were obtained. The trajectory and velocity information of tracer particles in the rotating flow field were obtained by the corresponding analysis software. Then, through the analysis and modeling of quantitative experimental data, the flow behavior characteristics and movement law of titanium alloy melt in the mold cavity under different mold speeds were studied. The results show that: 1 . When the mold is still, the front edge of the filling fluid forms a curved surface with the curvature center pointing to the outside of the mold; when the mold rotates, the front edge of the liquid flow forms a curved surface with the curvature center pointing to the inside of the mold; 2 . With the increase of the mold rotation speed, the speed of the fluid filling the mold increases significantly; when the rotational speed is greater than $120 \mathrm{rpm}$, the fluid still has a certain driving force in the mold center far away from the gate It is good for filling the inner corner of mold with fluid; 3 . When the rotational speed of centrifugal casting of titanium alloy reaches $45 \mathrm{rpm}$ or above, typical turbulent vortices appear in the wake; with the increase of rotating speed to 180 rpm, the average curvature radius of turbulent vortices first increases and then decreases, and reaches the minimum value of $0.67 \mathrm{~cm}$ at $120 \mathrm{rpm}$.

Keywords: centrifugal casting of titanium alloy; physical simulation experiment; particle tracer technology; filling velocity; morphology;

Corresponding author $\mathrm{Xu}$ Shen:

Email: shenxu@hust.edu.cn 


\section{Introduction}

Vertical centrifugal casting (VCC) is one of the important technologies for titanium alloy precision casting (Jianghong et al., 2017). Centrifugal motion can make the filling melt fill along the radial direction and form the free surface of the casting (Liu Baicheng et al., 2009).However, in centrifugal casting of titanium alloy, if the process is not properly controlled, the fluid will couple the effects of multiple force fields, resulting in severe disorder of gas-liquid mixed flow, and then produce shrinkage cavity and porosity defects; the centrifugal speed of mold is the key process parameter to control the filling effect and casting quality. (Sun Ji et al., 2018; shailesh Rao a et al., 2015; Prasad K S K et al., 2010; Jia 1 et al., 2016; Wang K et al., 2011). Physical simulation experiment is an important means to study the filling process of titanium alloy. Many researchers have carried out a series of physical simulation experiments on the fluid filling process of centrifugal casting. Prasad et al. Carried out cold simulation experiments with transparent water and 140ep oil with different viscosities, and studied the application of different rotational speeds on cylinder castings. It was found that the optimal speed required to form a uniform cylinder increased with the increase of cylinder thickness (Prasad K S K et al., 2010). Wu Shiping deduced the physical similarity model of titanium alloy VCC process to simulate the filling flow behavior of titanium alloy fluid under different gating systems and rotating speeds. It was found that the cross-sectional area of fluid in the runner decreased with the increase of filling length (Wu Shiping et al., 2011; Wu Shiping, 2008). Through the same water simulation experiment, Changyun 1 et al. Found that with the increase of the fluid filling speed, the fluid filling capacity first increases and then decreases with the increase of the rotation speed. (Changyun L, 2006) Ren et al. Studied the micro scale liquid metal filling flow mode in centrifugal casting process through physical simulation experiments. The results show that with the increase of rotating speed, the time required for fluid to reach the peak filling rate decreases sharply (Ren $\mathrm{m} x$ et al., 2014).

At present, there is little research on quantitative characterization of fluid motion 
state in the physical simulation experiment of vertical centrifugal casting process. The main reason is that the high-speed rotating factor of vertical centrifugation greatly increases the difficulty of on-line measurement of fluid physical data. In this paper, the fluid measurement method of particle tracking velocimetry (PTV) is used to obtain the quantitative data of fluid filling. PTV is to evenly put tracer particles into the experimental fluid to characterize the fluid movement, and then use image acquisition equipment to record continuous multi frame images with short exposure time. By analyzing the position of tracer particles in these sequential particle images, the motion characteristic values such as displacement and velocity of fluid motion are calculated. Thomas Hagemeier et al. studied the trajectories and rotation characteristics of solid particles in 2D fluidized bed by color PTV method, and characterized the solid particles with different sizes and densities with different color tracer particles. The results show that PTV method can well describe the movement of gas-solid two-phase flow. (Thomas Hagemeier et al., 2015; zhaochen Jiang et al., 2018) C.E.Estrada-Perez et al. studied the turbulent flow of HFE-301 in a rectangular channel by time-resolved particle tracking velocimetry, and obtained the characteristic values of its twodimensional velocity field and turbulence intensity (C.E. Estrada Perez et al., 2010). Yuichi Murai et al. (2013) measured the rotating flow field with PTV method, and reconstructed the 3D visualization flow field of local cylindrical wake and Taylor column. Therefore, PTV method is an effective means to obtain flow data.

Based on the above analysis, this study will take the physical simulation of vertical centrifugal casting of complex titanium alloy castings as the research object, combined with the mature PTV particle tracer technology, to obtain the flow behavior characteristics and movement law of the fluid in the mold cavity under different rotational speeds of VCC.

\section{Experimental methods}

The experimental flow chart is shown in Figure 1 below. The CMC concentration should be $6.8 \mathrm{~g} / \mathrm{L}$ for the similar fluid with viscosity of $83 \mathrm{cp}$ measured by viscometer. The CMC solution was dissolved in hot water according to the concentration in the 
mixer. After stirring for 2 hours and standing for 10 hours, the experimental similar fluid can be obtained, and then the experimental fluid is dyed blue, which is conducive to observe the filling morphology of the fluid. The experimental fluid was placed in a fluid storage container, and then the experimental tracer particles were put into the pipe with a funnel (holes were drilled on the pipe to release the particles). The centrifugal experimental platform was adjusted to the experimental speed, and the flow rate was set to $1.5 \mathrm{~L}$ (mold volume) through the fluid control system. Turn on the high-power LED light and high-speed camera and set it to continuous shooting mode, adjust the lens shooting range and exposure rate. After shooting, open the solenoid valve to start filling, and take photos of fluid filling. Finally, the trajectory and velocity of particles in continuous images are tracked by image processing software. The main experimental parameters are shown in Table 1.

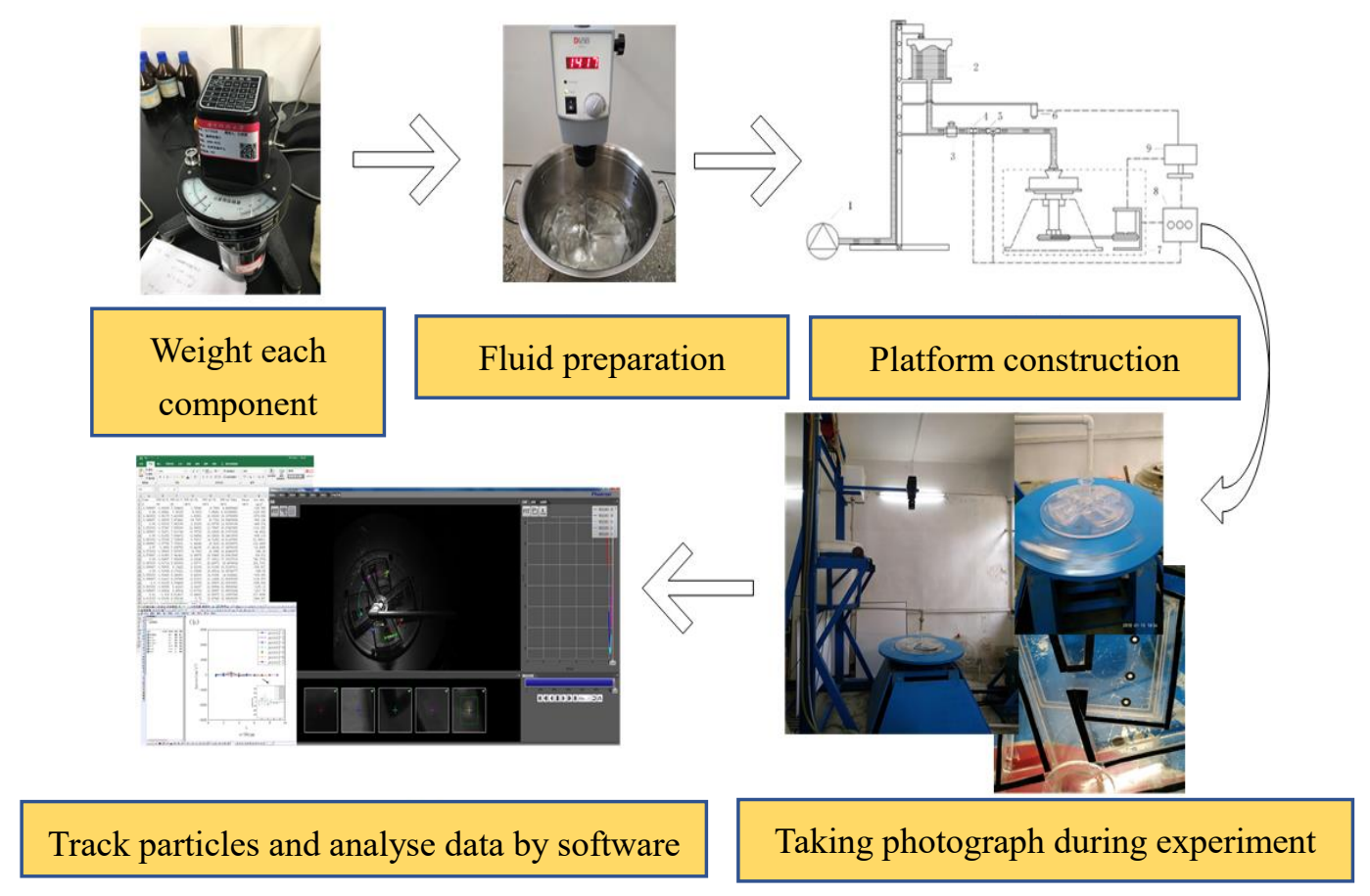

Fig.1 Experimental flow chart

Table 1 experimental parameters

\begin{tabular}{cccc}
\hline Parameters & Symbol & Value & Unit \\
\hline Fluid density & Pfluid & 0.998 & $\mathrm{~g} / \mathrm{cm}^{3}$ \\
flow & Q & 1.5 & $\mathrm{~L}$ \\
\hline
\end{tabular}




\begin{tabular}{cccc}
\hline $\begin{array}{c}\text { Pouring time } \\
\text { Ambient }\end{array}$ & Time & 8 & $\mathrm{~s}$ \\
Temperature & Temperature & 25 & ${ }^{\circ} \mathrm{C}$ \\
Fluid viscosity & $\eta$ & 83 & $\mathrm{cp}$ \\
Particle diameter & $\mathrm{d}$ & 0.4 & $\mathrm{~cm}$ \\
Particle density & Pparticle & 0.84 & $\mathrm{~g} / \mathrm{cm}^{3}$ \\
\hline
\end{tabular}

\subsection{Experimental platform}

The experimental platform is shown in Figure 2, including titanium alloy VCC physical simulation experimental platform and PTV shooting device. The titanium alloy VCC physical simulation experimental platform includes pouring system, centrifugal turntable and its control platform, mold and flow control system; PTV camera includes high-speed CCD camera, 200W high-power LED lamp and terminal upper computer. The fluid storage device is $2.2 \mathrm{~m}$ high. The centrifugal turntable rotates clockwise with the speed between 0-500rpm. A speed sensor is installed on the side of the centrifugal turntable to measure and feed back the rotating speed of the rotary table to the control platform of the centrifugal turntable in real time. The flow control system is composed of solenoid valve, flowmeter and control cabinet. The flowmeter feeds back to the control cabinet through the flow rate, and the control cabinet controls the solenoid valve switch through electrical signal, so as to control the pouring time and pouring flow. The detachable transparent plexiglass mold is fixed on the centrifugal turntable. The size of the die is $\Phi 50 \mathrm{~cm} * 7 \mathrm{~cm}$, and $\Phi 0.4 \mathrm{~cm}$ is drilled evenly in the four modules as the riser. Fig. 3 shows the experimental mold. This experiment only analyzes the flow pattern of single runner module. 


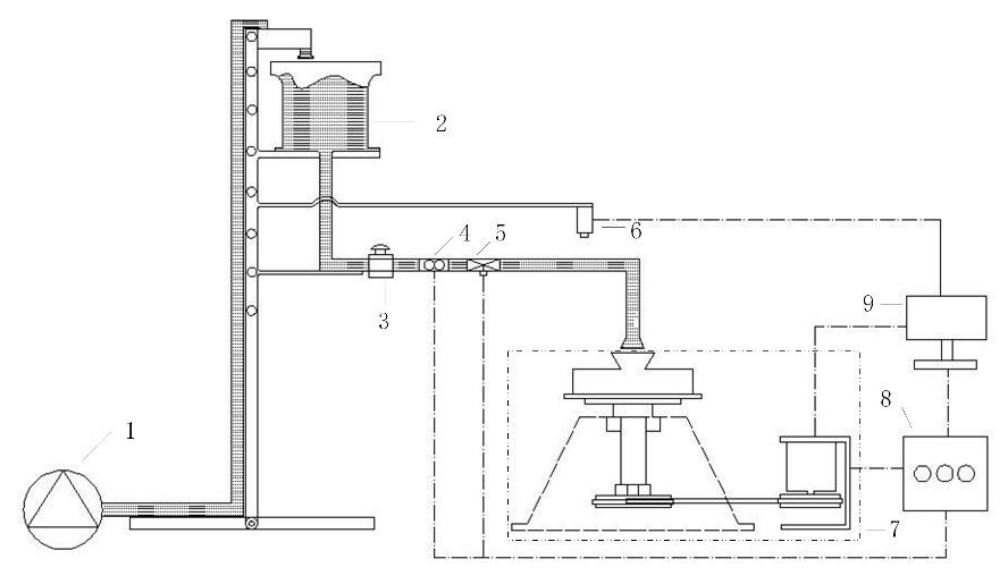

Figure 2 Schematic diagram of experimental platform (1. Fluid pump 2. Storage tank 3. Angle valve 4. Flowmeter 5. Solenoid valve 6. High speed camera 7. Centrifugal turntable and mold 8. Control cabinet 9. Computer)

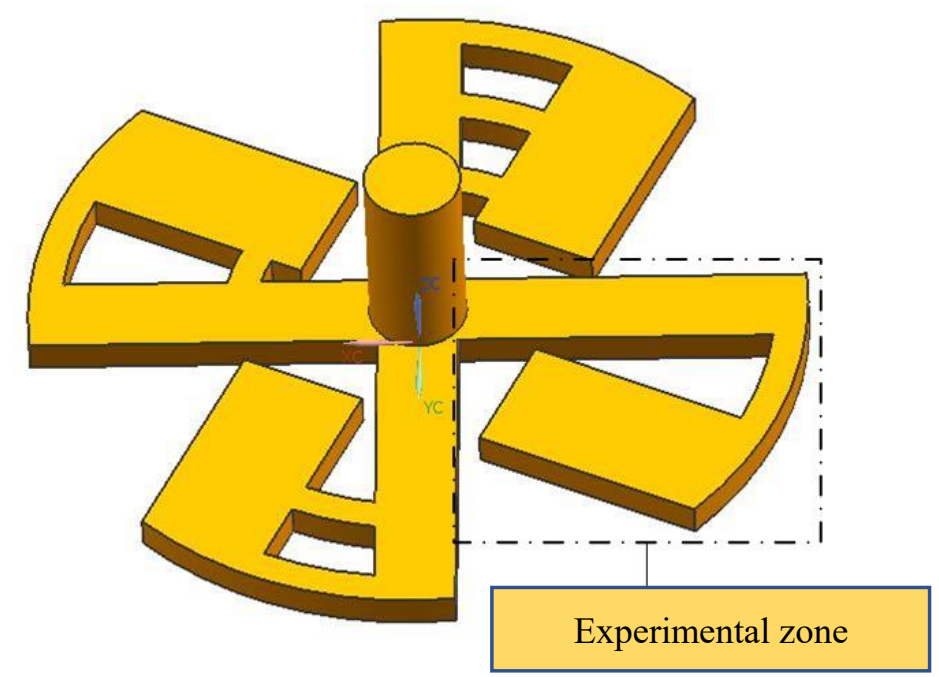

Figure 3 mold diagram

The internal flow field of titanium alloy melt filling was studied by physical simulation experiment method, and the required similarity fluid was deduced according to the similarity principle. The key technologies of two-dimensional particle image include: tracer particle selection, image acquisition, image processing, error analysis.

\subsection{Fluid selection}

The actual filling process of high temperature titanium alloy melt in centrifugal force field can be regarded as three-dimensional unsteady flow of viscous incompressible fluid with free surface. In the filling process of centrifugal casting, the 
liquid metal moves under the combined action of centrifugal force (Fce), Coriolis force (Fco), gravity (G) at a certain speed of filling fluid (as shown in the figure below). Based on the momentum transfer N-S equation, considering the geometric similarity, kinematic similarity and dynamic similarity, as well as the structural complexity and process complexity of actual castings, the similarity criteria (Froude number, Euler number, Reynolds number, etc.) in the process of fluid movement are derived by using the principle of similarity transformation.

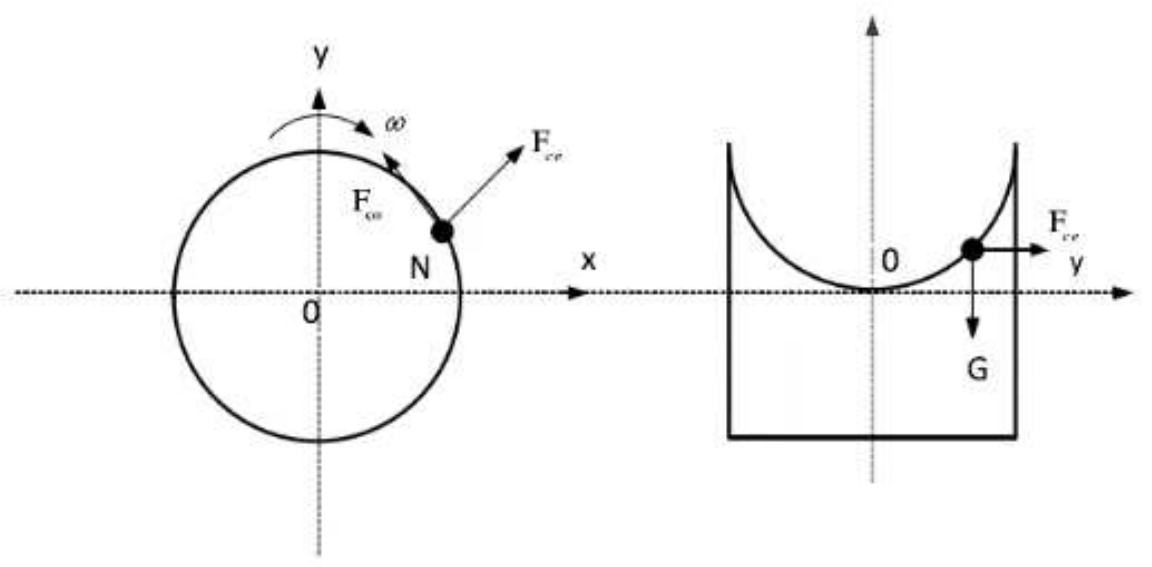

Fig. 4 force analysis of micro element

Where centrifugal force $F_{c e}=m \omega^{2} r$; Coriolis forc $F_{c o}=2 n\left(\omega \omega V_{c}\right) \quad\left(V_{C}\right.$ : Velocity of fluid relative to turntable); Gravity $G=n g$ 。Considering that gravity and Coriolis force have less effect than centrifugal force in vertical centrifugal casting, viscous force and inertial force play a decisive role at this time. Therefore, Reynolds number is selected as the standard number to obtain the following formula:

$$
\frac{\rho_{1} \omega_{1} l_{1}}{\eta_{1} \mu_{1}}=\frac{\rho_{2} \omega_{2} l_{2}}{\eta_{2} \mu_{2}}(2-1)
$$

Considering the similarity of dynamics, the above equation is simplified as:

$$
\frac{\rho_{1}}{\eta_{1}}=\frac{\rho_{2}}{\eta_{2}}(2-2)
$$

In this experiment, carboxymethyl cellulose aqueous solution was used as the experimental fluid, its density was $0.998 \mathrm{~g} / \mathrm{cm}^{3}$, while the density of titanium alloy melt was $4.11 \mathrm{~g} / \mathrm{cm}^{3}$, and the viscosity was 0.32663 pas. Substituting into formula 2-2, 
the viscosity of carboxymethyl solution meeting the similarity criterion should be 0.083 pas.

\subsection{Measuring method}

Particle tracking velocimetry (PTV) is to distribute a certain number of tracer particles in the flow field, and the pulsed laser sheet light source is incident into the measured flow field area. Through continuous exposure for many times, the images of particle position in the flow field at different times are obtained. The tracer particles and the fluid have a fixed following property. The fluid flow field is obtained by analyzing the motion of the tracer particles in the image. The concentration of tracer particles in PTV is low, and there is no interaction between particles, so it can track the movement of a single particle. In order to obtain more accurate fluid flow field, repeated experiments are needed to obtain a large number of data. In this paper, a tracking particle with a density of 0.84 and a diameter of $0.4 \mathrm{~cm}$ is used. The particle is bright yellow and its gray value is large in transparent liquid, so that it can be recognized by computer. The camera used in this paper is IDT high-speed camera, and the frame rate is $1800 \mathrm{hz}$. The high-speed camera is installed vertically above the mold, and the focus corresponds to the mold center. Before shooting, the mold was calibrated in advance.

\subsection{Data processing method}

The tracer particle is bright yellow, which is different from the fluid particle in gray scale and particle size. Based on the characteristics of particle swarm motion and particle size matching, the position of particles in each image is recognized and obtained. The position coordinates of particles in each image are output, and the velocity and acceleration are calculated based on the time difference between each image. The output data takes the lower left corner of the image as the default origin and adopts the right-hand coordinate system. According to the mold rotation speed, the coordinates and velocities of particles in the rotation coordinate system are output by matrix coordinate transformation. The rotation coordinate system takes the center of the mold as the origin and the center of the runner as the $\mathrm{R}$ axis. The position relationship of particles in the rotating coordinate system and the natural coordinate 
system is shown in the formula (2-3). The natural coordinate system takes the lower left corner of the image as the origin, and the right is the $\mathrm{X}$ axis; the rotation coordinate system takes the mold rotation axis as the rotation center, and the central axis of the mold runner is the $\mathrm{X}$ axis. The schematic diagram is shown in Figure 5.

Among them, $\left(\begin{array}{ll}x_{0} & y_{0}\end{array}\right)$ represents the default coordinate system of image analysis software; $\mathrm{K}_{\mathrm{x} 1}$ and $\mathrm{Y}_{\mathrm{y} 1}$ represent the coordinates of any point $\mathrm{K}$ in the translation coordinate system with the same origin as the rotation coordinate system; $\mathrm{K}_{\mathrm{x} 2}$ and $\mathrm{K}_{\mathrm{y} 2}$ represent the coordinates of any point $\mathrm{K}$ in the rotation coordinate system corresponding to the rotating mold. $\Theta_{0}$ represents the clockwise angle between the $\mathrm{x}$ axis in the natural coordinate system and the $\mathrm{x}$-axis at the initial moment of the rotating coordinate system. $\mathrm{n}$ is the mold angular velocity, in radians per second; $\mathrm{t}$ is the mold rotation time, in seconds.

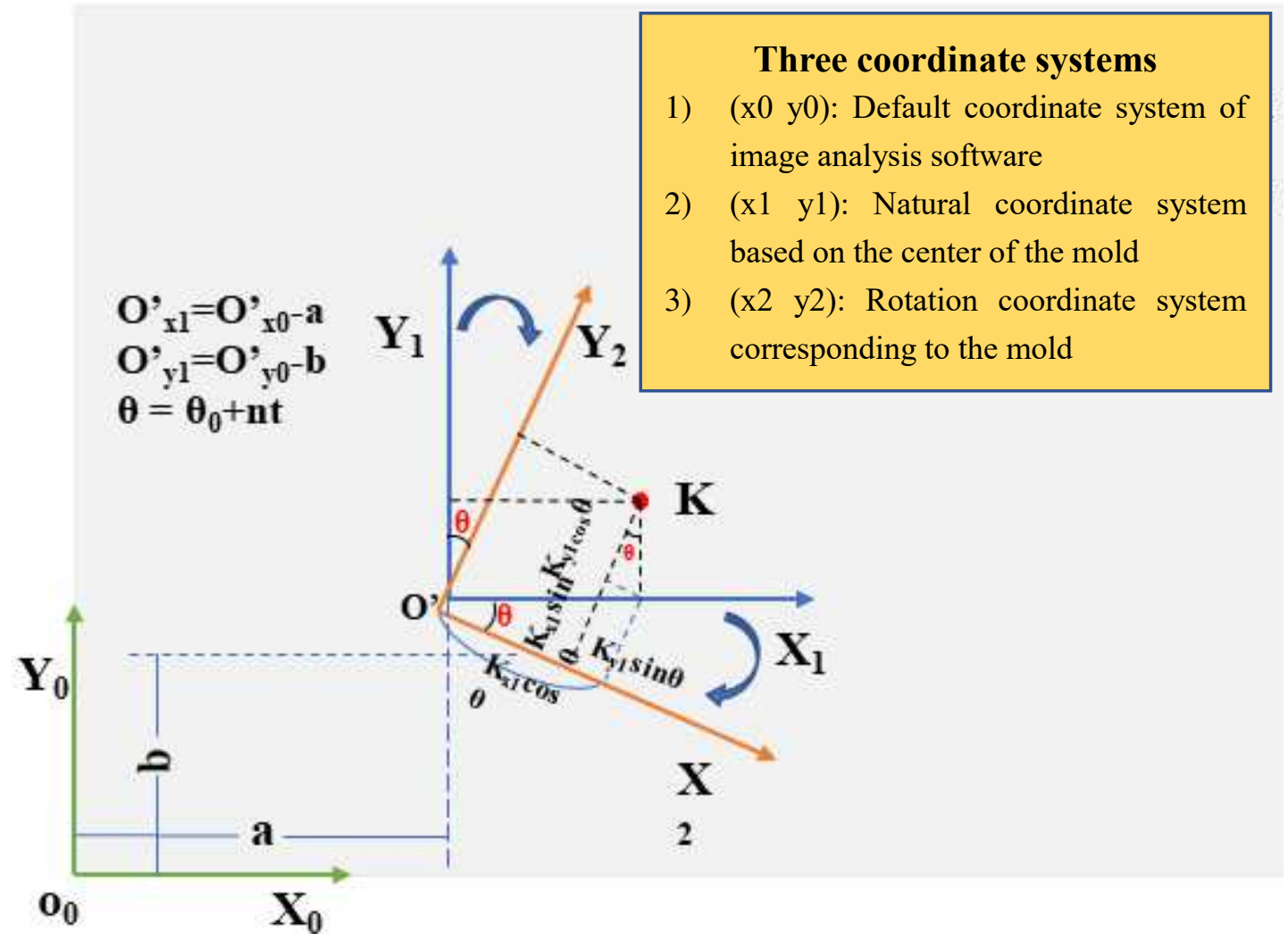

Fig.5 Coordinate axis transformation 


$$
\begin{gathered}
{\left[K_{x 2} K_{y 2}\right]=\left[K_{x 1}-a K_{y 1}-b\right]\left[\begin{array}{cc}
\cos \theta & \sin \theta \\
-\sin \theta & \cos \theta
\end{array}\right]} \\
\theta=\theta_{0}+n t
\end{gathered}
$$

\section{Experimental results and analysis}

In order to better analyze the model, the following basic assumptions are made in this paper:

(1) The continue medium model assumes that the fluid is composed of fluid micro clusters, which continuously fill the space occupied by the fluid, ignoring the internal molecular spacing and molecular motion.

(2) The fluid is incompressible.

(3) The viscosity coefficient remains unchanged.

\subsection{Morphology of fluid front at different mold speeds}

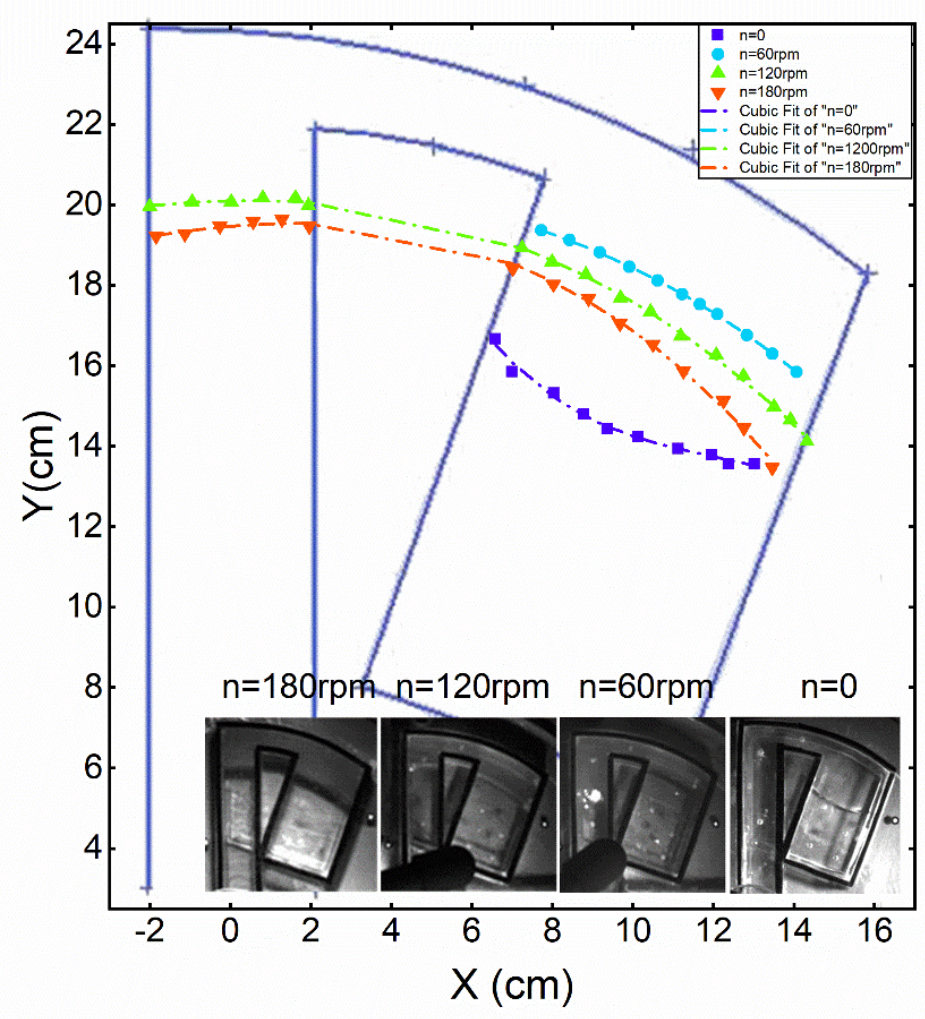

Fig.6 Front of filling fluid at $t=4 \mathrm{~S}$ at different rotating speeds

Fig. 6 shows the fluid morphology at $t=4 \mathrm{~S}$ at speeds of $0,60,120$ and $180 \mathrm{rpm}$. 
When the mold is still, the front edge of the filling fluid forms a curved surface with the curvature center pointing to the outside of the mold; when the mold is rotating, the front edge of the liquid flow forms a curved surface with the curvature center pointing to the inside of the mold. At the same time, when the rotating speed is high, the fluid filling area also increases.

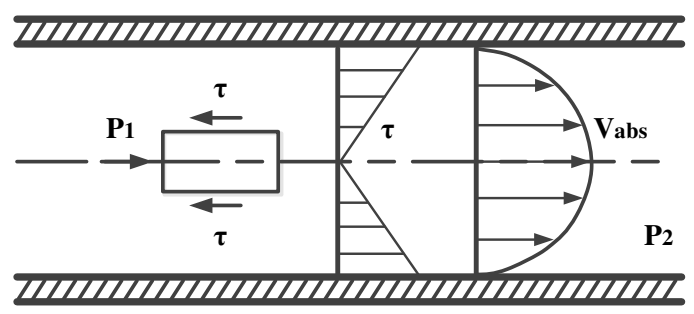

(a)

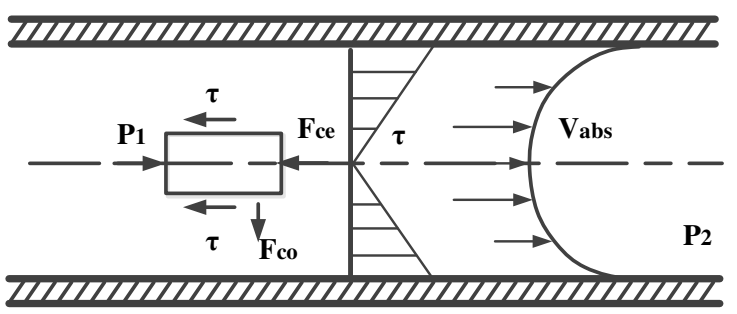

(b)

Fig.7 Force diagram of fluid micro mass

(a) fluid force when mold is still (b) fluid force during mold rotation

As shown in Figure 7 above, the overall stress diagram of fluid during mold rotation is shown. Among them, $\mathrm{P} 1$ is the mold pressure, $\mathrm{P} 2$ is the cavity pressure, $\tau$ is the shear stress caused by fluid viscosity, $\mathrm{F}_{\mathrm{ce}}$ and $\mathrm{F}_{\mathrm{co}}$ are the centripetal force and Coriolis force of the fluid under the rotating condition respectively. Centrifugal force and Coriolis force can only change the direction of fluid movement, but they cannot change its size. When the mold is still, due to the wall resistance on both sides of the fluid, the central velocity of the fluid is large, and the front edge of the fluid forms a paraboloid with the curvature center pointing to the opposite direction of the motion direction; when the mold is rotating, under the action of centrifugal force, the front edge of the fluid forms a paraboloid with the curvature center pointing to the direction of the rotation center. And with the increase of mold speed, the centrifugal force increases and the curvature of the curve decreases

\subsection{Velocity distribution of fluid at different mold rotation speeds}

According to the actual characteristics of centrifugal casting, experiments were designed at six rotational speeds which are shown in Table 2 below.

Table 2 experiment number

\begin{tabular}{lllllll}
\hline No. & 1 & 2 & 3 & 4 & 5 & 6 \\
\hline
\end{tabular}




\begin{tabular}{ccccccc}
\hline $\begin{array}{c}\text { Rotation rate } \\
(\mathrm{rpm})\end{array}$ & 0 & 30 & 45 & 60 & 120 & 180 \\
\hline
\end{tabular}

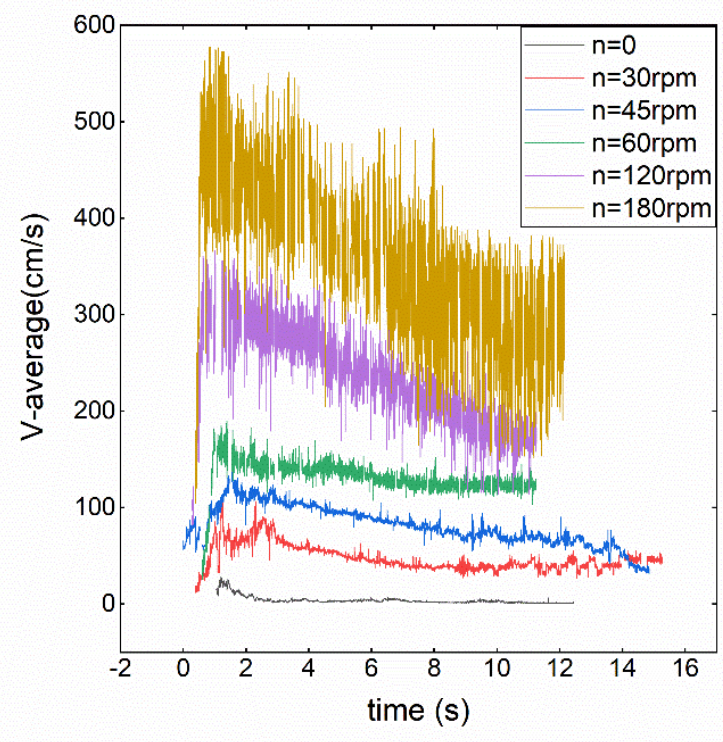

Fig. 8 fluid velocity at different speeds in natural coordinate system

The velocity of fluid in natural coordinate system $\left(\begin{array}{ll}x_{0} & y_{0}\end{array}\right)$ at various speeds is shown in Fig. 8. Because of the following relationship between the fluid velocity in two different coordinate system (the natural coordinate system and the rotating coordinate system):

$$
\left[\begin{array}{ll}
V_{x 2} & V_{y 2}
\end{array}\right]=\left[\begin{array}{ll}
V_{x 1} & V_{y 1}
\end{array}\right]\left[\begin{array}{cc}
\cos \theta & \sin \theta \\
-\sin \theta & \cos \theta
\end{array}\right]
$$

The filling velocity of the fluid in the rotating coordinate system is obtained as shown in the Fig.9 below. 
(a)

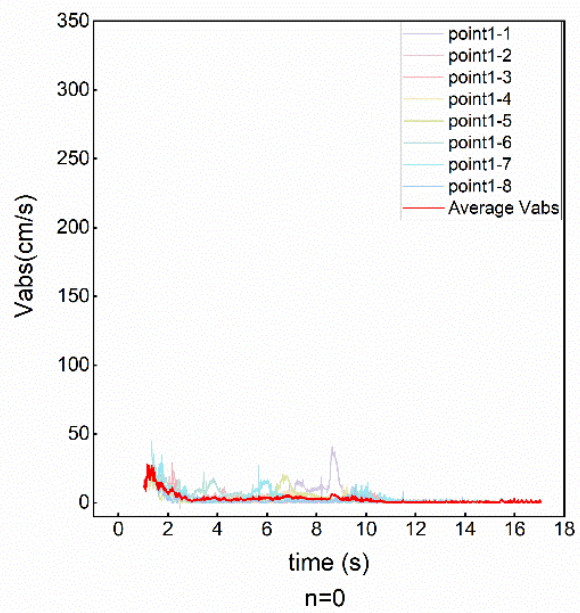

(c)

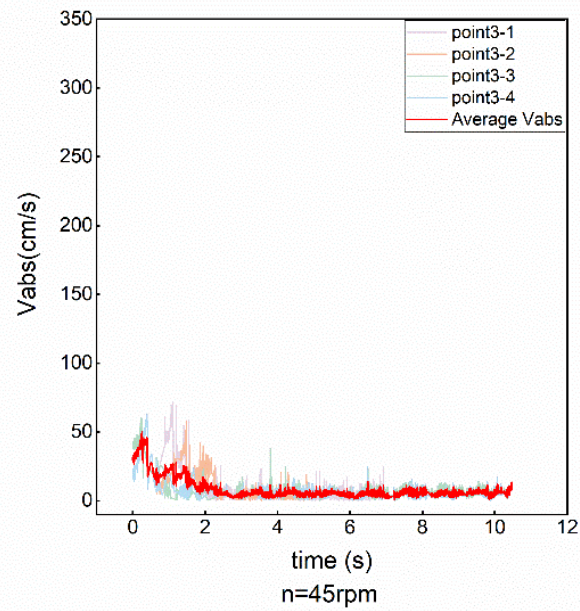

(e)

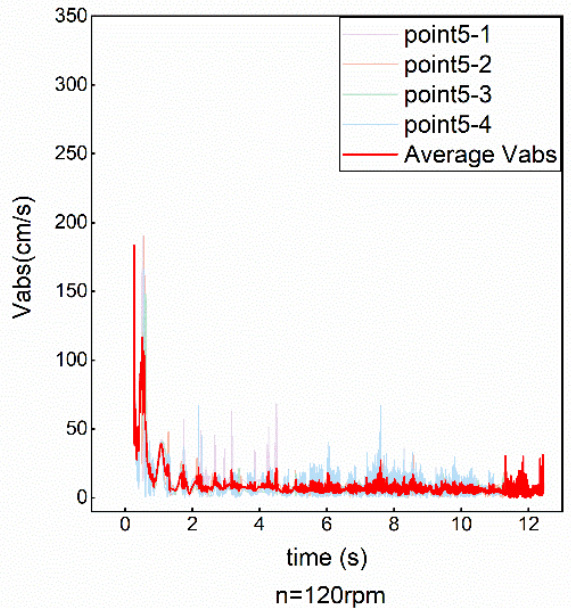

(b)

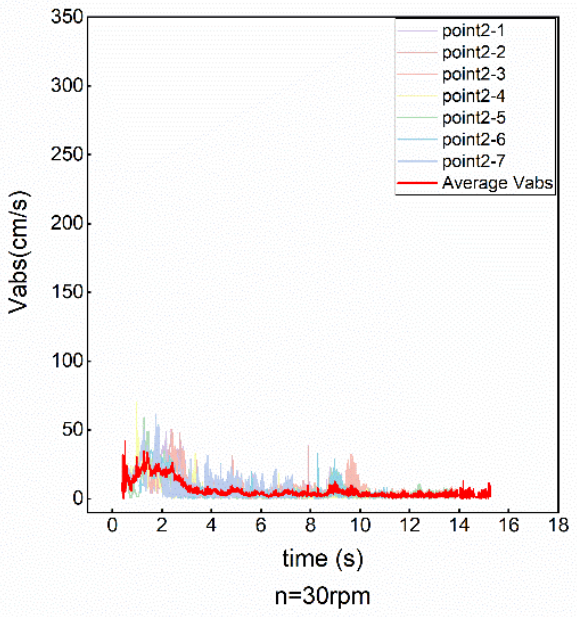

(d)

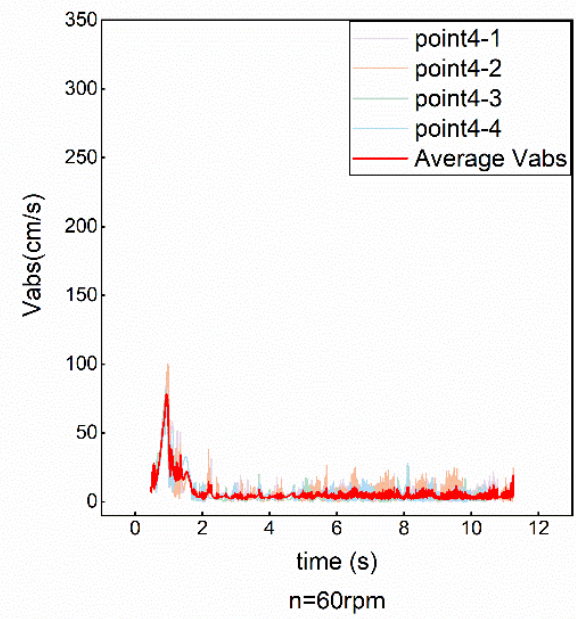

(f)

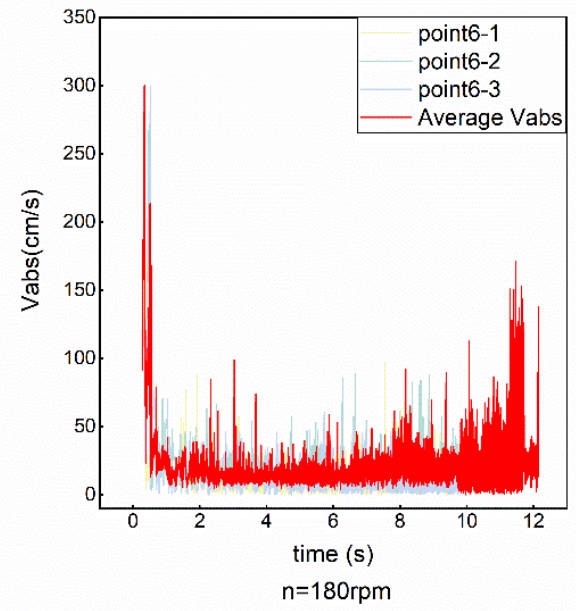

Fig.9 Fluid velocity at different speeds (a) speed is 0 (b) speed is 30 RPM (c) speed is 45 RPM (d) speed is $60 \mathrm{rpm}$ (E) speed is 120 RPM (f) speed is $180 \mathrm{rpm}$

It can be seen from the figure that with the increase of centrifugal speed, the speed 
of fluid filling mold increases. When the mold is still, the fluid filling velocity is between $0 \sim 50 \mathrm{~cm} / \mathrm{s}$; when the mold speed is below $45 \mathrm{rpm}$, the fluid filling speed does not increase significantly. When the mold speed reaches $60 \mathrm{rpm}$, the filling speed peak reaches $100 \mathrm{~cm} / \mathrm{s}$; when the mold speed reaches $180 \mathrm{rpm}$, the fluid filling speed peak reaches $300 \mathrm{~cm} / \mathrm{s}$. At the later filling stage, the fluid still has a certain filling speed. Such a large filling speed is conducive to filling the mold with fluid and reducing the occurrence of central shrinkage and porosity.

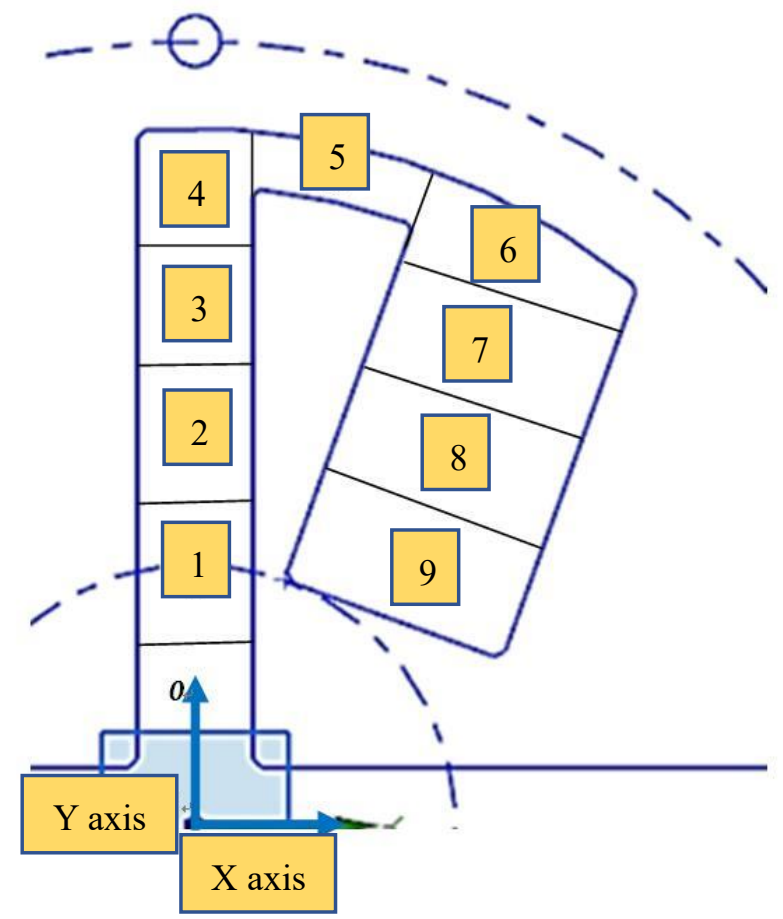

Fig.10 mold partition diagram

According to the force characteristics, the mold is divided into ten areas, as shown in Fig. 10. The average velocity of tracer particles in each area of the mold under each rotating speed condition is counted, that is, the average spatial velocity, as shown in Fig. 8. Calculate and count the average velocity of particles in each area under each rotating speed, and the results are shown in Fig. 11. It can be seen that the rotational speed of fluid in the mold follows the rule of first increasing and then decreasing. In area 3, the particle velocity reaches the maximum. This is because before the particles reach the corner of the mold, the speed of the particles gradually increases under the action of centrifugal force; when the particles reach area 4, they are subjected to the pressure of the mold opposite to the motion direction, and the kinetic energy is lost and the 
movement direction changes, and the velocity decreases rapidly. At the end of filling (area $8 \sim$ area 10), the filling velocity of fluid tends to 0 . In order to get better quality castings, the fluid should be evenly filled. At the speed of $120 \mathrm{rpm}$ and $180 \mathrm{rpm}$, the fluid still has a certain speed in the later stage, which is the optimal filling state. It is found that with the increase of the rotational speed, the velocity of the fluid passing through the bend zone (area 4-5) increases significantly.

(a)

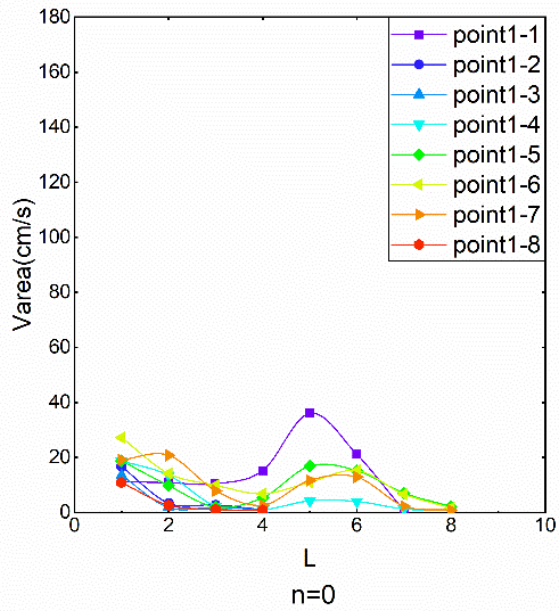

(c)

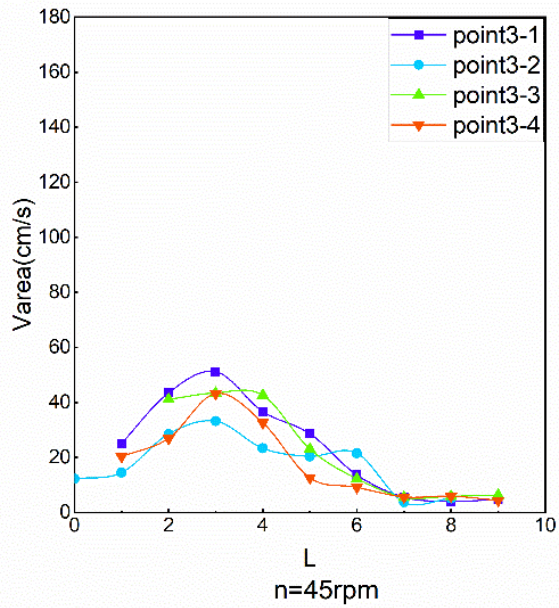

(b)

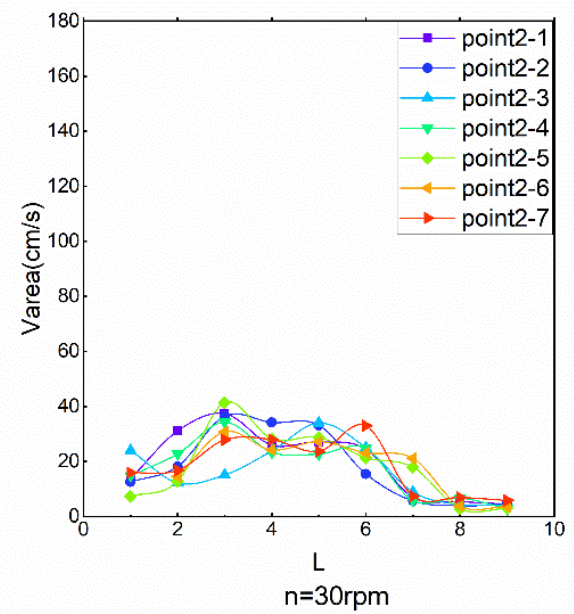

(d)

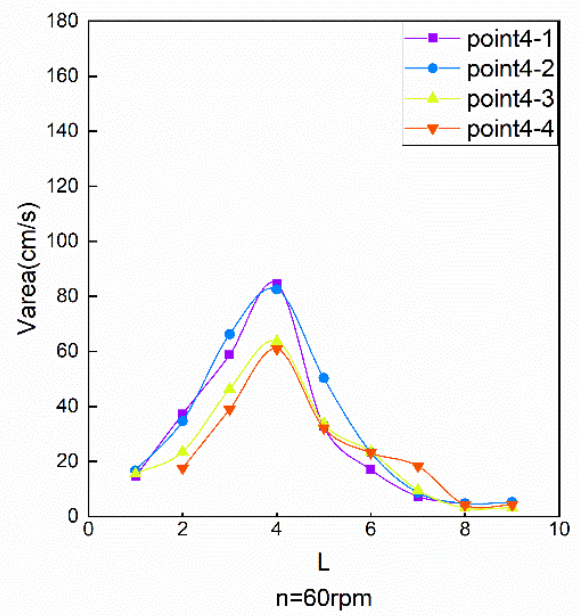


(e)

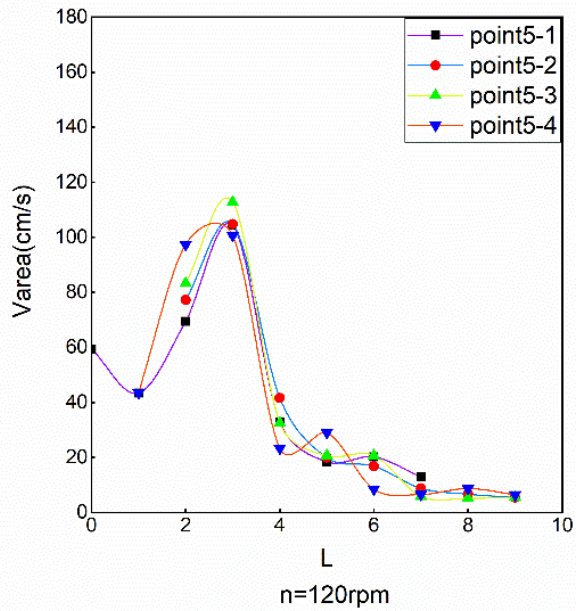

(f)

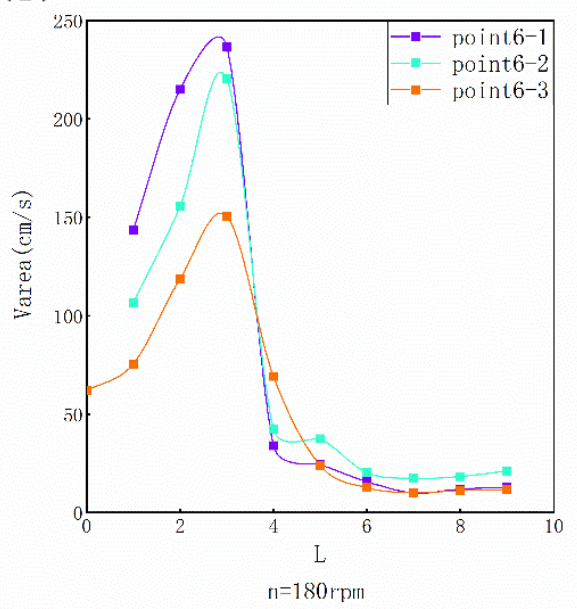

Fig. 11 Average velocity of fluid at different positions of the mold at different rotation speeds (a) is 0 (b) $30 \mathrm{rpm}$ (c) $45 \mathrm{rpm}$ (d) $60 \mathrm{rpm}$ (e) $120 \mathrm{rpm}$ (f) $180 \mathrm{rpm}$

Fig. 12 shows the average velocity of all particles at different positions of the mold at different speeds. It can be seen from the figure that when the mold is still, the velocity of fluid filling in the bend area (area 4-5) is relatively small, which is about $10 \mathrm{~cm} / \mathrm{s}$; when the mold is rotating, with the increase of mold speed, the velocity of fluid passing through the bend area is larger, and the average speed of fluid passing through the bend area is at $180 \mathrm{rpm}$ The degree is more than $200 \mathrm{~cm} / \mathrm{s}$. In casting, when the fluid passes through the curved area too small, it is easy to crystallize without filling the mold. Therefore, centrifugal casting can improve this situation. 


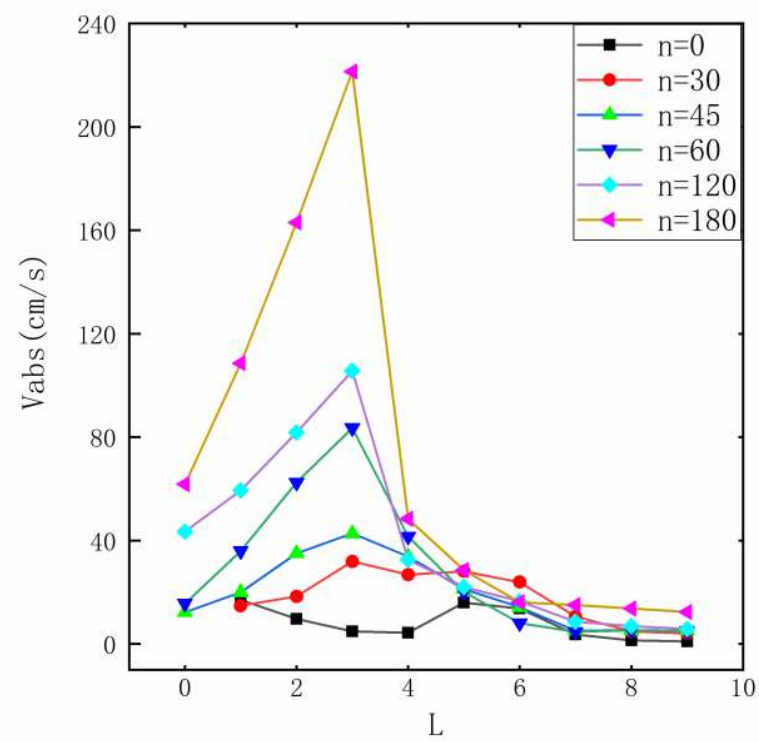

Fig. 12 Average velocity of all particles at different positions of the mold at different rotation speeds

According to the momentum theorem, the fluid impact force on the mold is $F_{\text {impact }}=\rho s\left(v-v_{0}\right)^{2}$, where $\left(v-v_{0}\right)=$ at. Fig. 13 shows the variation of the acceleration of the tracer particle with time at different rotating speeds. The red curve represents the average acceleration at different times. It can be seen that the fluid acceleration varies from $-1500 \mathrm{~cm} / \mathrm{s}^{2} \sim 1500 \mathrm{~cm} / \mathrm{s}^{2}$ under non rotating condition, and the fluid acceleration is larger in $0-11 \mathrm{~s}$, and tends to 0 after $11 \mathrm{~s}$. When the rotating speed is $30 \mathrm{rpm}$, the fluid acceleration varies from $-5000 \mathrm{~cm} / \mathrm{s}^{2} \sim 5000 \mathrm{~cm} / \mathrm{s}^{2}$, and the acceleration is larger between 0 and $11 \mathrm{~s}$. From $11 \mathrm{~s}$ to the end of filling, the fluid maintains a small acceleration. When the rotating speed is $45 \mathrm{rpm}$, the fluid acceleration varies from $-10000 \mathrm{~cm} / \mathrm{s}^{2}$ to 8000 $\mathrm{cm} / \mathrm{s}^{2}$, and the acceleration is large between 0 and $11 \mathrm{~s}$. The fluid maintains a small acceleration from $11 \mathrm{~s}$ to the end of filling. When the rotating speed is $60 \mathrm{rpm}$, the fluid acceleration changes from $-10000 \mathrm{~cm} / \mathrm{s}^{2}$ to $10000 \mathrm{~cm} / \mathrm{s}^{2}$; at $120 \mathrm{rpm}$, the fluid acceleration changes from $-100000 \mathrm{~cm} / \mathrm{s}^{2} \sim 100000 \mathrm{~cm} / \mathrm{s}^{2}$; at $180 \mathrm{rpm}$, the fluid acceleration changes from $-150000 \mathrm{~cm} / \mathrm{s}^{2}$ to $150000 \mathrm{~cm} / \mathrm{s}^{2}$. The results show that with the increase of mold speed, the pressure of mold under fluid particles increases in a multiple law. 
(a)

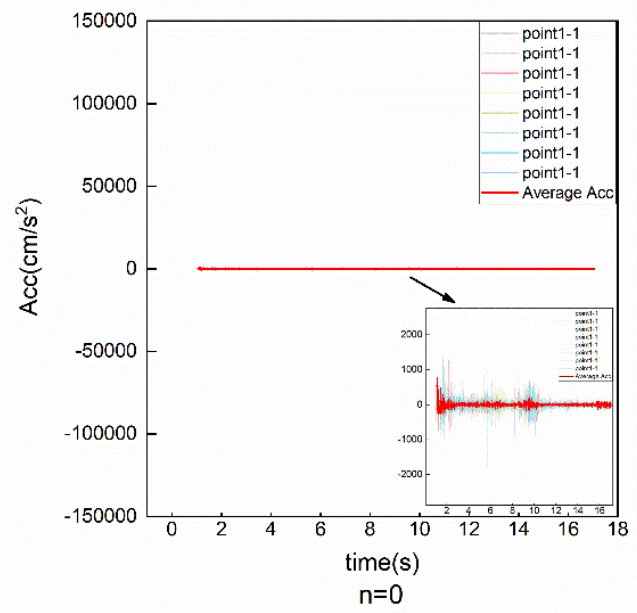

(c)

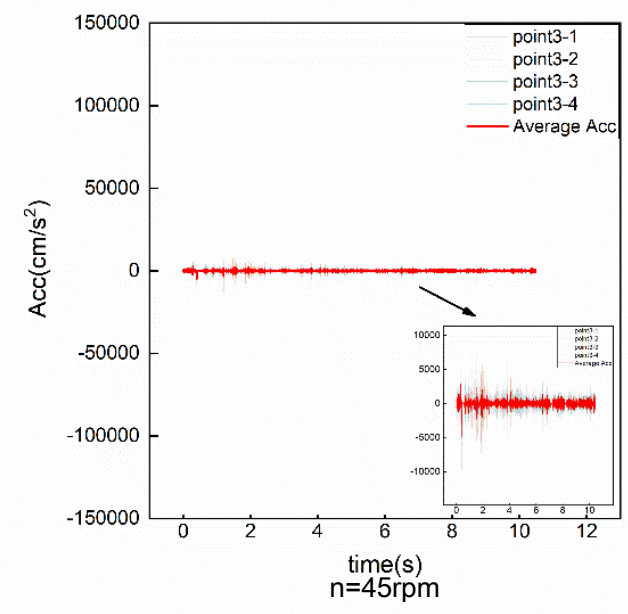

(e)

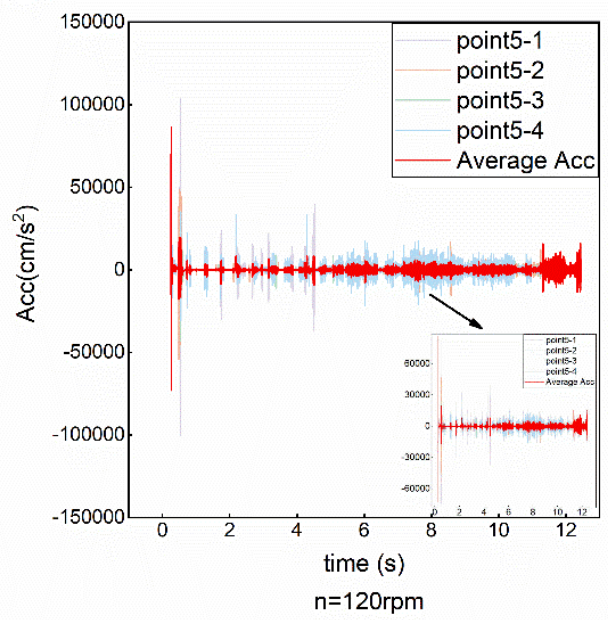

(b)

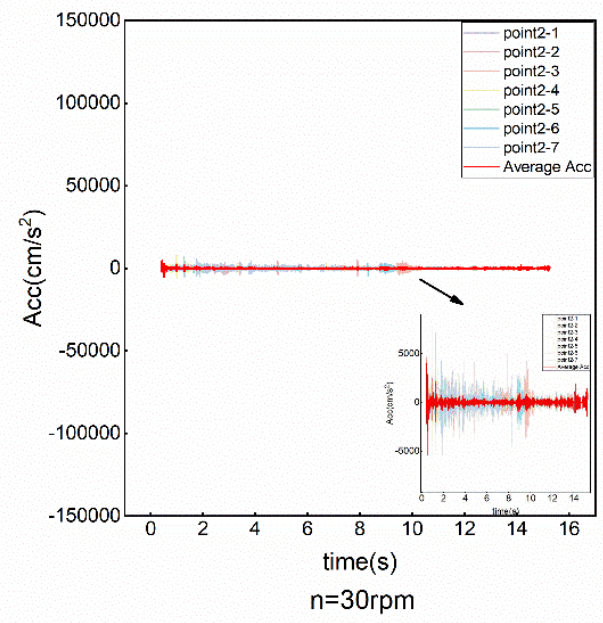

(d)

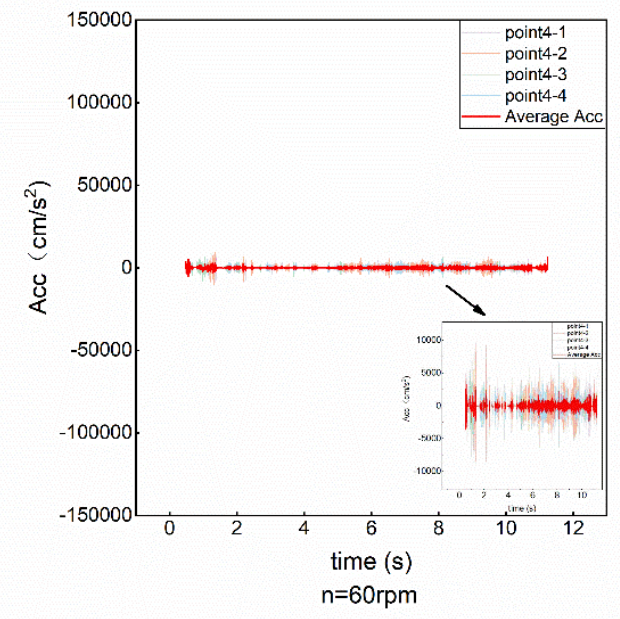

(f)

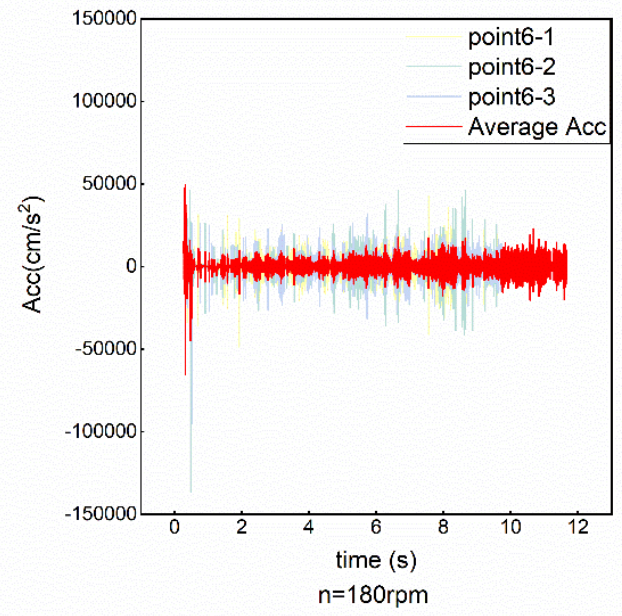

Figure 13 fluid acceleration at different mold rotation speeds (a) 0 (b) 30rpm (c) 45rpm (d) 60rpm (E) 120rpm (f) 180rpm

Fig. 14 shows the average acceleration statistics of tracer particles in different mold areas at different rotational speeds. It can be seen that under the non rotating 
condition, the fluid acceleration varies from $-60 \mathrm{~cm} / \mathrm{s}^{2}$ to $80 \mathrm{~cm} / \mathrm{s}^{2}$, and the maximum acceleration is about $50 \mathrm{~cm} / \mathrm{s}^{2}$ in the first section of the mold. The acceleration of fluid changes from -20 to $20 \mathrm{~cm} / \mathrm{s}^{2}$. When the rotating speed is $30 \mathrm{rpm}$, the fluid acceleration varies from $-80 \mathrm{~cm} / \mathrm{s}^{2}$ to $100 \mathrm{~cm} / \mathrm{s}^{2}$, and the maximum acceleration is about $80 \mathrm{~cm} / \mathrm{s}^{2}$ in the second to fourth range of the mold. The acceleration of fluid varies from $-30 \sim 10$ $\mathrm{cm} / \mathrm{s}^{2}$. When the rotating speed is $45 \mathrm{rpm}$, the fluid acceleration varies from $-200 \mathrm{~cm} / \mathrm{s}^{2}$ to $200 \mathrm{~cm} / \mathrm{s}^{2}$. The acceleration reaches the maximum in the third to fourth range of the mold, and its absolute value can reach $200 \mathrm{~cm} / \mathrm{s}^{2}$. The acceleration of fluid varies from -50 to $10 \mathrm{~cm} / \mathrm{s}^{2}$. When the rotating speed is $60 \mathrm{pm}$, the acceleration of fluid varies from $-400 \mathrm{~cm} / \mathrm{s}^{2} \sim 500 \mathrm{~cm} / \mathrm{s}^{2}$, and the acceleration reaches the maximum in the third to fourth range of the mold, and its absolute value can reach $500 \mathrm{~cm} / \mathrm{s}^{2}$. The acceleration of fluid varies from -20 to $20 \mathrm{~cm} / \mathrm{s}^{2}$. When the rotating speed is $120 \mathrm{rpm}$, the fluid acceleration varies from $-1000 \mathrm{~cm} / \mathrm{s}^{2}$ to $2500 \mathrm{~cm} / \mathrm{s}^{2}$, and the maximum acceleration is obtained in the third to fourth area of the mold, and the absolute value can reach $2500 \mathrm{~cm} / \mathrm{s}^{2}$. The acceleration of fluid varies from -100 to $100 \mathrm{~cm} / \mathrm{s}^{2}$. When the rotating speed is $180 \mathrm{rpm}$, the fluid acceleration varies from $1500 \mathrm{~cm} / \mathrm{s}^{2}$ to $3000 \mathrm{~cm} / \mathrm{s}^{2}$, and the maximum acceleration is obtained in the third to fourth area of the mold, and its absolute value can reach $2800 \mathrm{~cm} / \mathrm{s}^{2}$. The acceleration of fluid varies from -80 to $120 \mathrm{~cm} / \mathrm{s}^{2}$.

From the above analysis, it can be seen that with the increase of rotation speed, the average peak stress in fluid region increases in multiple form. On the other hand, with the increase of rotation speed, the maximum impact force of fluid on the mold gradually increases, and the location of the maximum impact force moves backward; at the same time, with the increase of rotation speed, the driving force of fluid in the late filling stage also increases. As can be seen from Fig. 10 (b) (f), the fluid acceleration increases first, then decreases, and finally increases to zero. This is due to the increasing centrifugal pressure when the fluid enters the mold. The calculation formula of centrifugal pressure is as follows, in which the rotation radius $r$ reaches the maximum when the fluid enters the outermost part of the mold. When the fluid moves to the outermost part of the mold (area $4 \sim 5$ ), the fluid is subjected to the pressure opposite to the direction of motion on the mold wall, and the fluid acceleration 
decreases rapidly. When the fluid flows through the mold bend and enters into the inside of the mold, the gravity, centrifugal force and Coriolis force tend to be balanced, and the fluid acceleration tends to zero, and a stable free surface is formed as shown in Fig. $14(\mathrm{c} \sim \mathrm{d})$.

$$
P_{L}=\gamma\left[0.056\left(\frac{n}{100}\right)^{2} r^{2}+h\right]
$$

Where $\mathrm{P}_{\mathrm{L}}$ is the centrifugal pressure strength produced by the fluid to each layer, $\mathrm{N} / \mathrm{cm}^{2} ; \gamma$ is the fluid gravity, $\mathrm{N} / \mathrm{cm}^{3} ; \mathrm{R}$ is the rotation radius of the fluid particle, $\mathrm{cm}$; $\mathrm{n}$ is the casting speed, $\mathrm{r} / \mathrm{min}$; $\mathrm{h}$ is the static head height.

(a)

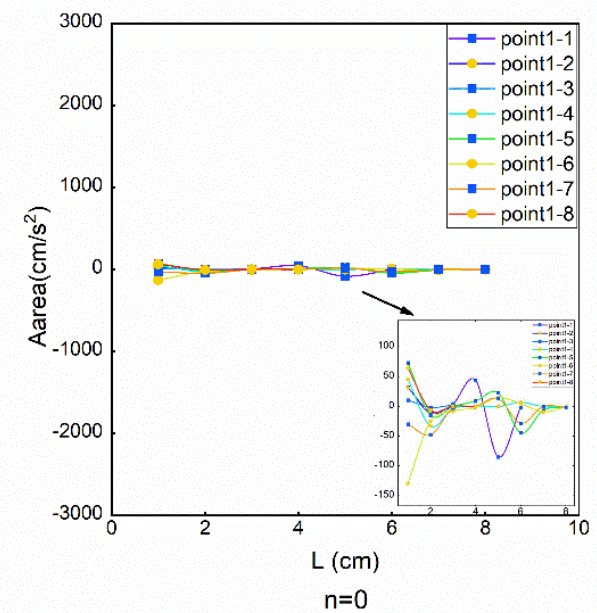

(c)

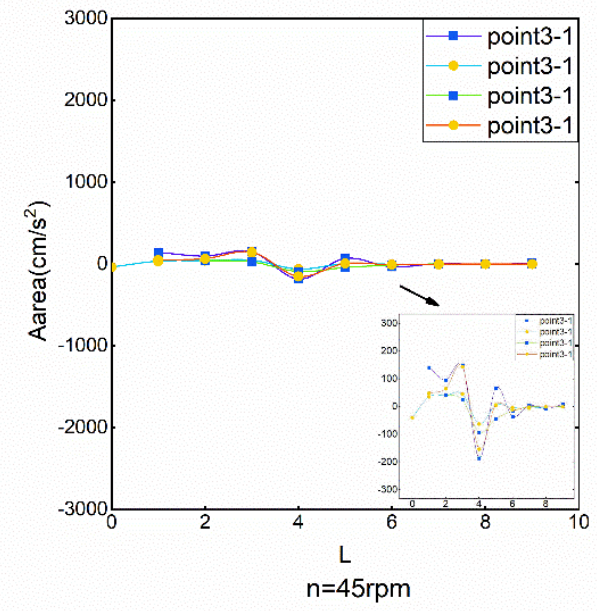

(b)

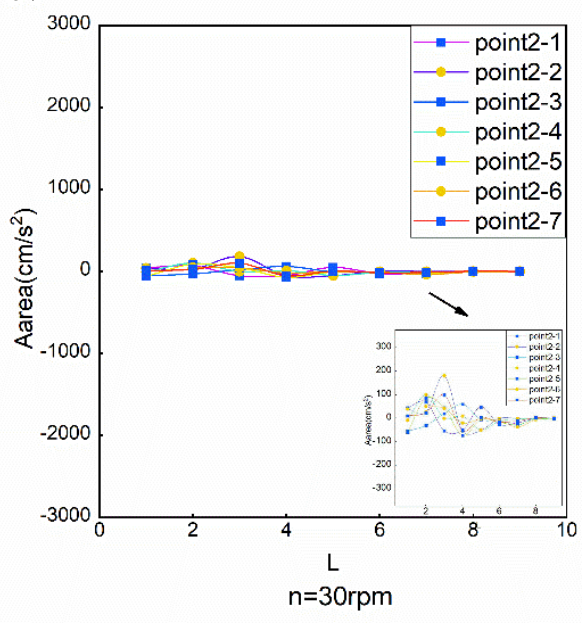

(d)

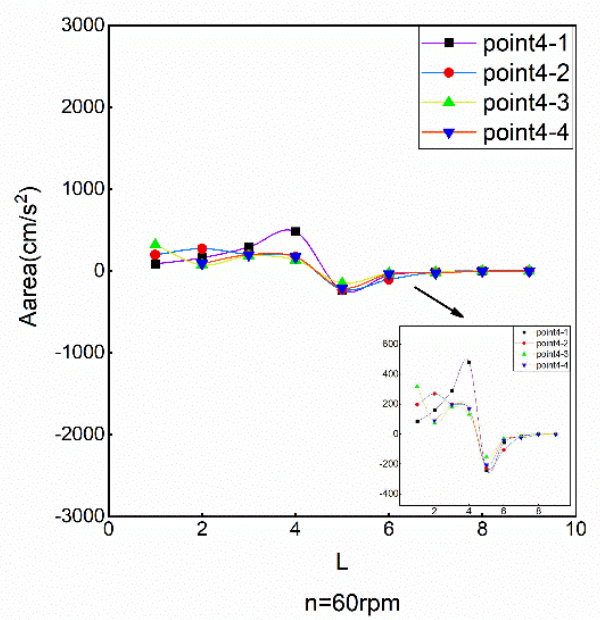


(e)

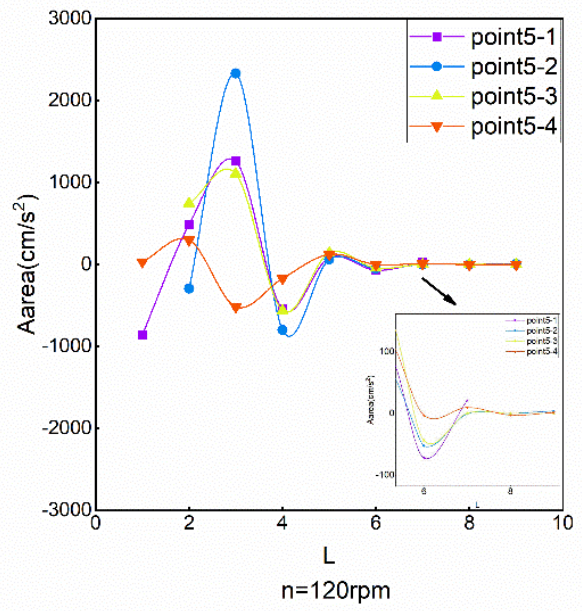

(f)

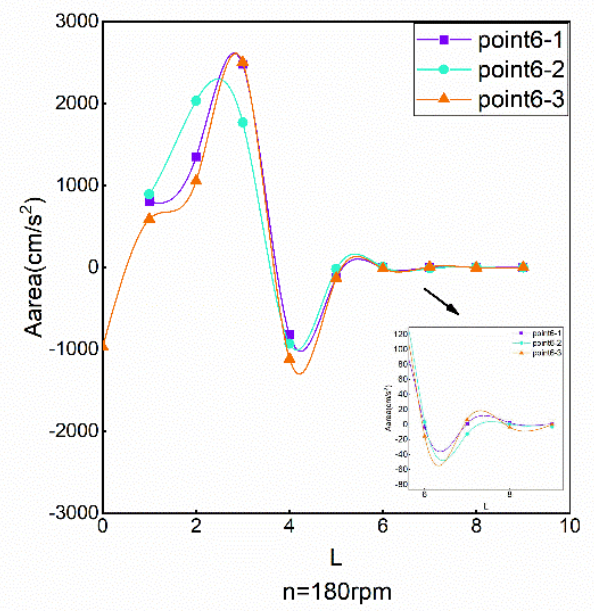

Fig. 14 Acceleration of fluid movement at different areas of the mold at different rotation speeds (a) 0 (b) $30 \mathrm{rpm}$ (c) $45 \mathrm{rpm}$ (d) $60 \mathrm{rpm}$ (e) $120 \mathrm{rpm}$ (f) $180 \mathrm{rpm}$

\subsection{Fluid trajectory at different mold rotation speeds}

The trajectories of tracer particles at different rotational speeds are shown in Fig. 15. It can be seen that typical turbulent vortices appear in the wake of the fluid under rotating conditions, and with the increase of rotation speed, the average diameter of the turbulent vortices decreases significantly, and the fluid tends to move along the edge of the mold. The appearance of turbulent vortex is due to the viscous effect of turbulent fluid. The vortices can deform, split and diffuse under the viscous action, and these motions are random. The vorticity equation is used to describe the vortex quantitatively, as shown in formula $3-2$.

$$
\frac{D \Omega^{*}}{D^{*}}=\frac{1}{\mathrm{Pe}} \nabla^{2} \Omega^{2}
$$

Where $\frac{1}{\mathrm{Pe}}$ is equivalent to the diffusion coefficient of vortices. 

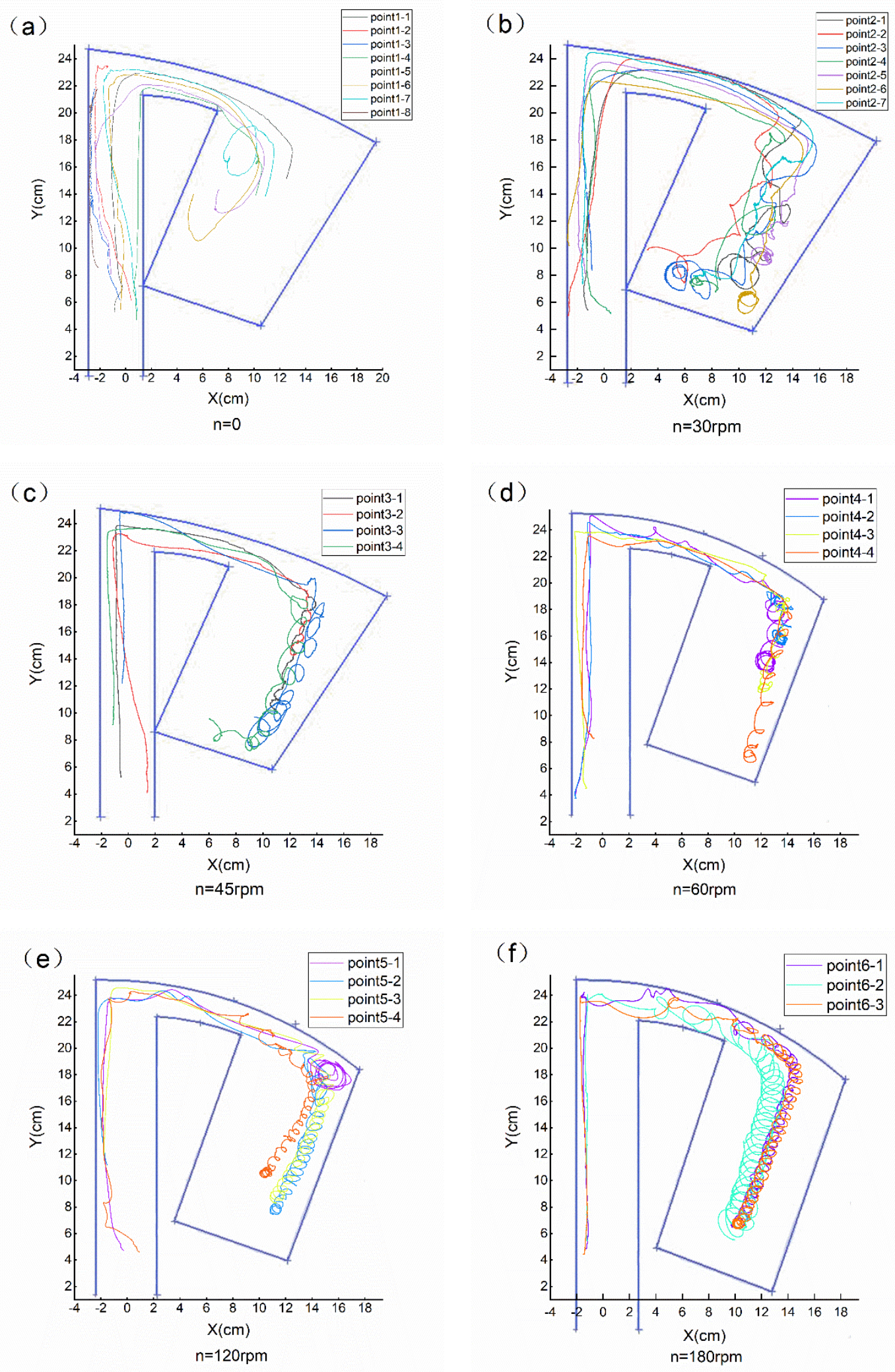

Fig. 15 Fluid trajectory at different mold speeds (a) 0 (b) 30rpm (c) 45rpm (d) 60rpm (E) 120rpm (f) 180rpm

The average radius of curvature of turbulent vortex at different speeds is calculated and counted. The results are shown in Fig. 16. With the increase of mold rotation speed 
from $45 \mathrm{rpm}$ to $180 \mathrm{rpm}$, the average curvature radius of turbulent vortex first increases and then decreases, and reaches the minimum value of $0.67 \mathrm{~cm}$ when the mold speed is $120 \mathrm{rpm}$. The more uniform and fine turbulent vortices are, the more stable the filling fluid is, and the castings with dense microstructure and good mechanical properties are easily formed.

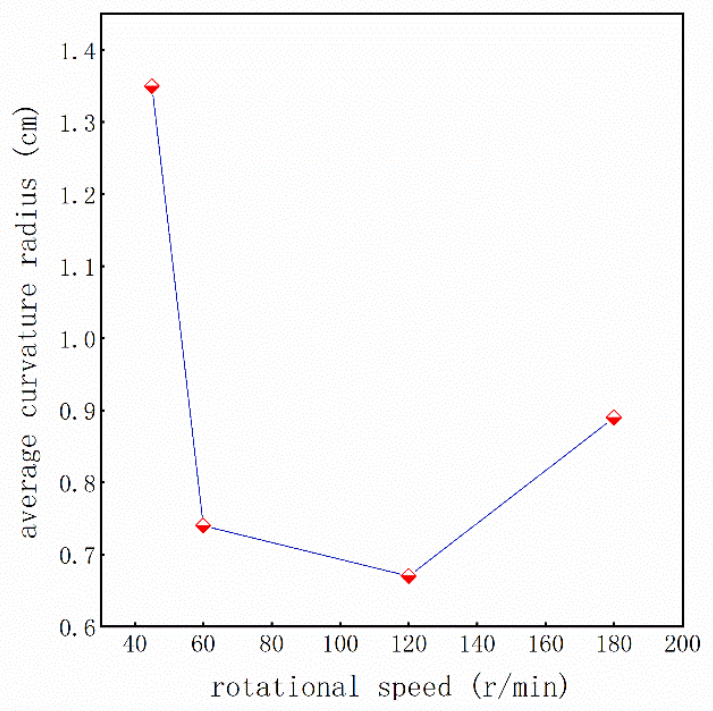

Fig. 16 Average curvature radius of turbulent vortex at different speeds

Equation 3-3 calculates the Reynolds number of fluid at different speeds.

$$
\mathrm{Pe}=\frac{\rho v d}{\mu}
$$

Where the characteristic length $d=\frac{4 A}{D}$

The fluid density $\rho$ is $0.998 \mathrm{~g} / \mathrm{cm}^{3}$, and the dynamic viscosity coefficient $\mu$ is 83 Pas. $\mathrm{A}$ is the cross section of the pipe and $\mathrm{D}$ is the wetted perimeter. The characteristic length $\mathrm{d} 1=4.5 \mathrm{~cm}$ in the runner area, $\mathrm{d} 2=4.7 \mathrm{~cm}$ in the mold bend, $\mathrm{d} 3=7 \mathrm{~cm}$ in the flow field around the bend. $\mu$ is the characteristic velocity of the fluid.

Therefore, the Reynolds number of the fluid in the region after passing the bend, where $\mathrm{V} 1$ is the velocity of the fluid in the natural coordinate system. When re is less than 2300 , that is, the fluid velocity is less than $55.66 \mathrm{~cm} / \mathrm{s}$, the fluid is laminar flow. The velocity of fluid changes with time and area in natural coordinate system. It can be 
seen from the figure that when the rotating speed reaches $45 \mathrm{rpm}$, the fluid is turbulent, which also corresponds to the turbulent vortex in Fig. 7 at that time.

\section{Conclusion}

Based on the similarity criterion, a physical simulation experiment was carried out on the filling process of titanium alloy in vertical centrifugal casting. The particle tracking method was used to obtain the morphological characteristics of titanium alloy fluid filling and the quantitative data such as the trajectory and velocity of fluid micro clusters in the filling process. Through statistics and analysis, the following conclusions are obtained:

(1) When the mold is still, the whole fluid fills forward along the mold direction; when the mold rotates, the fluid first fills into the mold along the bottom of the mold and the side wall opposite to the rotation direction. At the same time, when the mold is still, the front edge of the filling fluid forms a curved surface with the curvature center pointing to the outside of the mold; when the mold is rotating, the front edge of the liquid flow forms a curved surface with the curvature center pointing to the inside of the mold.

(2) In vertical centrifugal casting of titanium alloy, with the increase of mold speed, the peak pressure of fluid particles on the mold increases by multiple times, and the position of the peak pressure moves to the inside of the mold. When the mold speed reaches $120 \mathrm{rpm}$, the fluid still has a certain driving force in the mold center far away from the gate, which is conducive to the filling of the inner corner of the mold.

(3) Under the experimental conditions, when the mold speed reaches $45 \mathrm{rpm}$, typical turbulent vortices appear in the wake. With the increase of mold speed from 45 rpm to $180 \mathrm{rpm}$, the average curvature radius of turbulent vortex first increases and then decreases, and reaches the minimum value of $0.67 \mathrm{~cm}$ at $120 \mathrm{rpm}$. On the other hand, when the mold speed reaches $120 \mathrm{rpm}$ or above, the fluid passes through the mold bend at a significantly faster speed and reaches the inside of the mold. 


\section{Author information}

\subsection{Affiliation}

State Key Laboratory of Materials Processing and Die \& Mould Technology, Huazhong University of Science \& Technology, Wuhan, Hubei, 430074, People's Republic of China

Yajun Yin, Xin Peng, Gen Xiao, Xu Shen*, Peng Wan, Xiaoyuan Ji, Jianxin Zhou

AIMTEC Material Co., Ltd., Beijing, 100095, People's Republic of China Xiwang Qie

\subsection{Authors Contribution}

All authors developed the theory and performed the computations. Also, all authors discussed the results and contributed to the final manuscript.

\subsection{Corresponding author}

Correspondence to Xu Shen.

\section{Data availability}

The data that support the findings of this study are available from the corresponding authors, upon reasonable request.

\section{Ethical declarations}

\subsection{Ethical approval}

For this type of study, formal consent is not required. 


\subsection{Consent to participate}

The authors voluntarily agreed to participate in this research study.

\subsection{Consent to publish}

The author transfers to Springer the non-exclusive publication rights and he warrants that his/her contribution is original and that he/she has full power to make this grant. The author signs for and accepts responsibility for releasing this material on behalf of all co-authors. This transfer of publication rights covers the non-exclusive right to reproduce and distribute the article, including reprints, translations, photographic reproductions, microform, electronic form (offline, online), or any other reproductions of similar nature. The author may self-archive an author-created version of his article on his own website and his institution's repository, including his final version; however he may not use Springer's PDF version which is posted on www.springerlink.com. Furthermore, the author may only post his version provided acknowledgment is given to the Journal and Springer as one of the original places of publication and a link is inserted to the published article on Springer's website.

\subsection{Competing interests}

The authors declare no competing interests.

\section{Funding}

This work is supported by National Key R\&D Program 2020YFB1710100. The authors would also like to acknowledge financial support from the National Natural Science Foundation Council of China (Grant No. 51605174, No. 51775205, No.51905188).

\section{References}

Yongting $\mathrm{Hu}$, Jianbin Shao, Gang Chen. Comparative study of several PTV 
algorithms[C]. Proceedings of the 21st National Symposium on hydrodynamics and the 8th National Symposium on hydrodynamics and the Symposium on ship and Ocean Engineering Hydrodynamics. 2008. (In Chinese).

Hong Jiang, Xiaodan Zhang. Research and application status of titanium alloy at home and abroad[J]. Advanced Materials Industry, 2017(3):7-10. (In Chinese).

Baicheng Liu, Tianyou Huang, et al. Foundry forming manual[M]. Beijing: Chemical Industry Press, 2009,277-313. (In Chinese).

Ji Sun, Changfa Xie, Lijun Sun, et al. Analysis and Research on centrifugal casting defects[J]. Foundry Equipment \& Technology, 2018(2). (In Chinese).

Shiping $\mathrm{Wu}$, Jun Zhang, Qin $\mathrm{Xu}$, et al. Numerical simulation of mold filling and solidification process in centrifugal casting [J]. Research of Foundry Equipment, 2008, 6: 25-27. (In Chinese).

Shiping Wu, Jingjie Guo, Jun Zhang, et al. The research progress of precision forming theory and technology of titanium alloy casting[J]. Materials China, 2011(07):1623. (In Chinese).

Naijun Zhou, Engineering Fluid Mechanics[M]. Beijing: China Machine Press, 2014: 195-209. (In Chinese).

Alberini F, Liu L, Stitt E H, et al. Comparison between 3-D-PTV and 2-D-PIV for determination of hydrodynamics of complex fluids in a stirred vessel[J]. Chemical Engineering Science, 2017, 171:189-203.

Alvarez Chavez, J. A., Offerhaus, H. L., Sierra-Calderon, A., \& Plascencia-Barrera, G. (2018). In-house PIV laser system design and development for measuring the velocity of liquids. Abstract from XVI Symposium of Mexican Students and Studies in the UK 2018, Southampton, United Kingdom. https://doi.org/10.5281/ zenodo. 1421958

C.E. Estrada-Perez, Y.A. Hassan, PTV experiments of subcooled boiling flow through a vertical rectangular channel, International Journal of Multiphase Flow, 2010, 36 (9) : 691-706,

Changyun L, Shiping W, Jingjie G, et al. Hydraulic modelling of mould filling behaviour during vertical centrifugal casting processing $[\mathrm{J}]$. International Journal 
of Cast Metals Research, 2006, 19(4):237-240.

Chirita G, Soares D, Silva F S . Advantages of the centrifugal casting technique for the production of structural components with Al-Si alloys[J]. Materials \& Design, 2008, 29(1):20-27.

Jia L, Liang Z, Xu D, et al. Effects of Centrifugal Forces and Casting Modulus on Structures and Mechanical Properties of Ti-6Al-4V Alloy[J]. Rare Metal Materials and Engineering, 2016, 45(3):581-587.

Prasad K S K, Murali M S, Mukunda P G. Analysis of fluid flow in centrifugal casting[J]. Frontiers of Materials Science in China, 2010, 4(1): 103-110.

Ren M X, Wang G T , Li B S , et al. Similar physical simulation of microflow in microchannel by centrifugal casting process[J]. Transactions of Nonferrous Metals Society of China, 2014, 24(4):1094-1100.

Shailesh Rao A, Tattimani M S , Rao S S . Effect of Rotational Speeds on the Cast Tube During Vertical Centrifugal Casting Process on Appearance, Microstructure, and Hardness Behavior for Al-2Si Alloy[J]. Metallurgical and Materials Transactions B, 2015, 46(2):793-799.

Thomas Hagemeier, Andreas Bück, Evangelos Tsotsas, Estimation of Particle Rotation in Fluidized Beds by Means of PTV, Procedia Engineering, 2015,102: 841-849,

Wang K, Sun W, Li B , et al. Microstructures in centrifugal casting of SiCp/AlSi9Mg composites with different mould rotation speeds[J]. Journal of Wuhan University of Technology: Materials Science, 2011, 26(3):504-509.

Yuichi Murai, Jozef H.A. Vlaskamp, Yuichi Nambu, etc. Off-axis PTV for 3-D visualization of rotating columnar flows[J]. Experimental Thermal and Fluid Science,2013, 51: 342-353.

Zhaochen Jiang, Thomas Hagemeier, Andreas Bück, Evangelos Tsotsas. Color-PTV measurement and CFD-DEM simulation of the dynamics of poly-disperse particle systems in a pseudo-2D fluidized bed[J]. Chemical Engineering Science,2018,179: $115-132$. 